\title{
PENGARUH WAKTU PEMADUAN BAGI TEKNIK PEMADUAN MEKANIK TERHADAP KEKERASAN PADUAN Al-10\%BERATTI
}

\author{
Adolf Asih Supriyanto \\ Lab Fisika, Prodi Teknik Mekatronika, Politeknik Enjinering Indorama, Purwakarta \\ Kembangkuning, Jatiluhur, 41152 Purwakarta, Jawa Barat \\ Email: adolf@pei.ac.id
}

\begin{abstract}
ABSTRAK
Pengaruh waktu pemaduan terhadap ukuran partikel dan kekerasan jasad hijau paduan Al10\% beratTi telah dilakukan dengan menggunakan teknik pemaduan mekanik. Plenetari model Fritsch Pulverisette-5 dengan kecepatan 360 putaran per menit dan bola stainless steel berdiameter $15 \mathrm{~mm}$ digunakan sebagai alat pemaduan. Asam stearik digunakan sebagai bahan mengawal proses selama proses pemaduan. Serbuk aluminium dan titanium dengan komposisi Al-10\%beratTi, asam stearik dan bola stainless steel dimasukkan kedalam Plenetari model Fritsch Pulverisette-5 dalam persekitaran gas argon. Rasio berat bola stainless steel terhadap berat serbuk adalah $20: 1$. Waktu pemaduan adalah 2, 5, 10, 15, 20 dan 30 jam dengan waktu istirahat selama 30 menit setiap 2,5 jam pemaduan untuk menghindari peningkatan suhu yang mendadak. Perubahan struktur dan morfologi serbuk selama proses pemaduan diamati menggunakan XRD, SEM dan EDX, sedangkan uji mikrokekerasan digunakan Vickers. Hasil yang diperoleh menggunakan XRD menunjukan bahwa puncak-puncak titanium semakin menghilang dengan bertambahnya waktu pemaduan, yang menujukkan bahwa telah terbentuk proses pemaduan dimana atom titanium masuk ke dalam matrik aluminium. Hasil SEM menunjukkan bahwa ukuran partikel Al-10\%beratTi semakin berkurang dengan bertambahnya waktu pemaduan. Hasil EDX menunjukkan bahwa serbuk yang dihasilkan adalah paduan biner Al-Ti. Hasil uji mikrokekerasan menunjukkan bahwa kekerasan semakin meningkat dengan bertambahnya waktu pemaduan.
\end{abstract}

Kata kunci: al-10\%beratTi, pemaduan mekanik, asam stearik, XRD, vickers.

\begin{abstract}
The influence of milling time on the particle size and hardness of Al-10\%wt.Ti green body has been carried out using mechanical alloying technique. A Fritsch Pulverisette-5 planetary type ball mill and ball size of $15 \mathrm{~mm}$ were used for the mechanical alloying with the rotational speed of about $360 \mathrm{rpm}$. Stearic acid was used as process control agent (PCA). Fine powders of aluminium and titanium were mixed in a weight ratio to give nominal composition of the Al-10wt.\%Ti, and then sealed under argon atmosphere in a cylindrical stainless steel container together with stainless steel balls. The weight ratio of balls-to-powder was $20: 1$. The milling times used were 2, 5, 10, 15, 20 and 30 hours respectively with a rest period of 30 minutes every 2.5 hours of milling to avoid increasing temperature suddenly. Changes in the structure and morphology of the powder during the milling process were observed using XRD, SEM and EDX while Vickers was used as hardness test. The results obtained using XRD showed that the peaks of Ti begin disappear with the increasing of milling time, which indicates the forming alloying of Ti atoms in the Al matrix. The SEM results showed that the size of Al-10\%wt.Ti particles decreases with increasing milling time. The EDX results confirmed that the nanocrystalline produced were binary alloy of Al-Ti. The microhardness test results showed that the hardness increases with increasing milling time.
\end{abstract}

Keywords: al-10\%wt.Ti, mechanical alloying, acid stearic, XRD, vickers.

\section{PENDAHULUAN}

Aluminium dikenal sebagai salah satu bahan logam ringan yang memiliki sifat-sifat agak lebut, mulur dan tidak kuat. Sifat bahan aluminium tersebut menyebabkan penggunaan bahan aluminium menjadi sangat terbatas. Walaupun demikian sifat mekanik bahan aluminium dapat diperbaiki melalui paduannya dengan logam lain. Salah satu pemadu logam lain tersebut adalah titanium [1]. Semenjak ditemukannya paduan Al-Ti, ternyata paduan ini telah dikenal sebagai salah satu bahan yang paling prospektif. Paduan ini dapat digunakan didalam industri luar angkasa dan berbagai kegunaan untuk peralatan mesin [2]. Paduan Al-Ti dapat juga diaplikasi pada suhu tinggi karena paduan ini antara lain memiliki ciri-ciri densitas yang rendah, titik lebur yang tinggi dan tahan terhadap korosi $[3,4]$. 
Salah satu teknik untuk memperoleh paduan logam Al-Ti berukuran nanopartikel adalah dengan teknik pelarutan padat [5]. Teknik pelarutan padat khususnya pemaduan mekanik lebih digemari oleh para peneliti karena teknik ini cukup mudah, murah, dapat dilakukan didalam suhu ruangan dan dapat menghasilkan produk dalam skala yang besar. Teknik pemaduan mekanik dapat juga menghasilkan paduan yang sukar dibuat melalui proses tuangan biasa terutama bagi unsur-unsur pemadu yang mempunyai titik lebur yang tinggi dan teknik ini merupakan teknik yang sangat baik untuk menghaluskan ukuran butiran [6-8].

Teknik pelarutan padat dengan bola pemadu bertenaga tinggi telah banyak digunakan oleh para peneliti untuk mensintesis berbagai senyawa paduan logam [9-11]. Teknik ini melibatkan proses patahan dan pengelasan dingin yang berulang dari partikel serbuk sebagai akibat berbenturan dengan bola pemadu berenergi tinggi. Bahan pelicin yang dikenali sebagai agen pengawal proses biasanya perlu ditambahkan pada campuran serbuk tersebut dengan tujuan untuk menghindari terjadinya perlekatan antara serbuk dengan bola atau serbuk dengan dinding, disamping itu juga untuk mengontrol proses patahan dan pengelasan dingin sewaktu pemaduan. Bahan-bahan organik yang biasa digunakan sebagai bahan pelicin antara lain adalah asam stearik, asam oksalik, heksana, etanol dan metanol. Diantara sekian banyak bahan pelicin asam strearik adalah bahan pelicin yang paling sering digunakan [7].

Dalam penelitian ini digunakan teknik pemaduan mekanik dan bahan pelicin asam stearik untuk memperoleh paduan Al-10\% beratTi. Tujuan penelitian ini adalah untuk mengetahui pengaruh waktu pemaduan terhadap perubahan ukuran partikel dan kekerasan paduan Al-10\% beratTi.

\section{METODOLOGI PENELITIAN}

Dalam metode penelitian ini akan diuraikan tentang bahan dan alat yang digunakan serta tata kerja dalam penelitian ini.

\subsection{Bahan}

Bahan-bahan yang digunakan dalam penelitian ini adalah serbuk aluminium dengan kemurnian $99 \%$ berukuran $71 \mu \mathrm{m}$ dan serbuk titanium dengan kemurnian 99,5\% berukuran $60 \mu \mathrm{m}$. Bahan lain yang digunakan adalah asam stearik $\left(\mathrm{CH}_{3}-\left(\mathrm{CH}_{2}\right)_{16}-\mathrm{COOH}\right)$ dan gas argon.

\subsection{Alat}

Peralatan yang digunakan dalam penelitian ini adalah alat penimbang, alat penekan 10 ton, dan alat pemadu bola planetari model Fitsch Pulverisette 5 dengan empat pemegang vial (wadah) berkapasitas $250 \mathrm{ml}$ untuk menghasilkan serbuk paduan Al-10\%beratTi. Bola yang digunakan sebagai pemadu untuk memadu berdiameter $15 \mathrm{~mm}$. Pemadu bola planetari, vial dan bola ditunjukkan dalam Gambar 1. Vial dan bola untuk memadu serbuk terbuat dari stainless steel. Peralatan lain adalah XRD, SEM dan EDX yang digunakan untuk mengamati perubahan struktur dan morfologi serbuk Al-10\%beratTi selama proses pemaduan. Vickers adalah alat yang digunakan untuk menguji mikrokekerasan serbuk Al-10\%beratTi.

\subsection{Tata Kerja}

Serbuk aluminium dan titanium masing-masing ditimbang dan dicampur mengikut komposisi 90\% berat aluminium dan $10 \%$ berat titanium. Asam stearik $\left(\mathrm{CH}_{3}-\left(\mathrm{CH}_{2}\right)_{16}-\mathrm{COOH}\right)$ ditambahkan ke dalam campuran serbuk tersebut sebanyak $4 \%$ daripada berat campuran serbuk di atas. Bola-bola pemadu dan campuran serbuk (aluminium, titanium dan asam starik) dimasukkan kedalam vial dengan rasio berat bola stainless steel terhadap berat serbuk adalah $20: 1$. Kemudian vial diisi dengan gas argon untuk menghindari oksidasi selama proses pemaduan berlangsung dan ditutup rapat. Proses pemaduan dilakukan dengan kecepatanan putaran 360 putaran per menit dan waktu pemaduan divariasikan 2, 5, 10, 15, 20 dan 30 jam dengan waktu istirahat selama 30 menit setiap 2,5 jam pemaduan untuk menghindari peningkatan suhu yang mendadak. Kemudian sebagian serbuk paduan Al-10\%beratTi yang diperoleh dilakukan karakterisasi dengan menggunakan XRD, SEM dan EDX. Sebagian yang lainnya dari serbuk yang diperoleh dijadikan pelet (jasad hijau) berdiameter $1 \mathrm{~cm}$ dengan mengenakan tekanan 10 ton. Kemudian dilakukan pencirian penguji mikrokekerasan Vickers dengan beban 100 gf. 


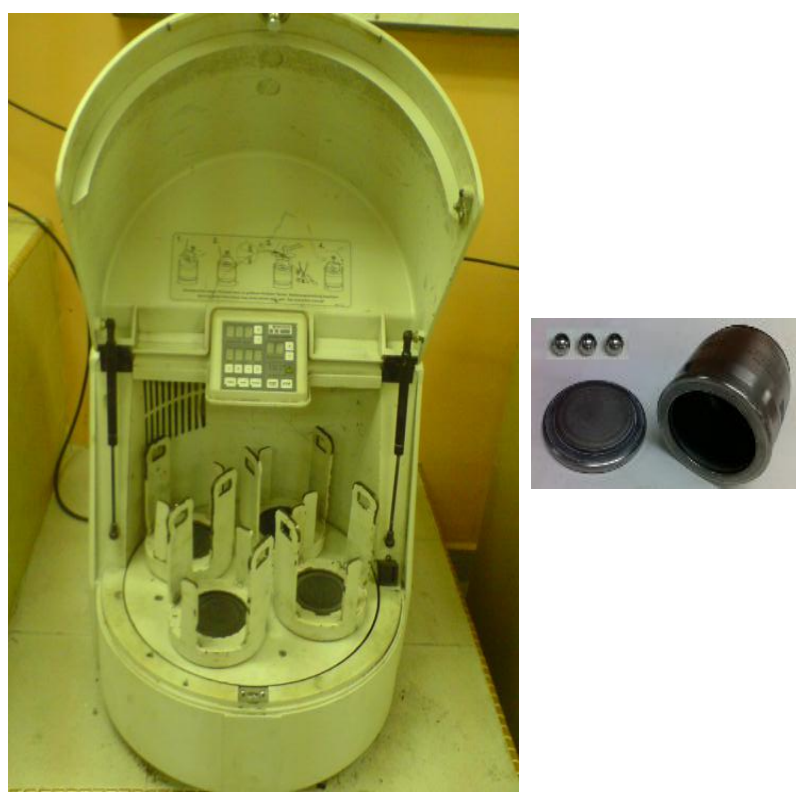

Gambar 1. Pemadu Bola Planetari, Vial Dan Bola

\section{HASIL DAN PEMBAHASAN}

Gambar 2 menunjukkan difraktogram serbuk Al-10\%beratTi setelah dipadu dengan waktu pemaduan sehingga 30 jam. Pada awal pemaduan selama 2 jam, puncak difraktogram unsur alumunium diamati dengan puncak yang tinggi sedangkan puncak difraktogram unsur titanium masih bisa diamati walaupun dengan puncak yang tidak terlalu tinggi. Dengan bertambahnya waktu pemaduan, puncak difraktogram bagi unsur aluminium dan titanium semakin bergeser ke kanan dan melebar seperti yang ditunjukkan dalam Gambar 3. Pelebaran puncak tersebut disebabkan oleh pengurangan ukuran partikel [13]. Puncak difraktogram untuk unsur titanium berangsur-angsur hilang dan menghilang ketika waktu pemaduan selama 30 jam (Gambar 2). Hal ini menunjukkan bahwa unsur Ti telah masuk kedalam matriks Al dan membentuk paduan Al-Ti [12].

Gambar 4 menunjukkan mikrograf SEM serbuk Al-10\%beratTi setelah dipadu selama 5 dan 20 jam. Setelah pemaduan selama 5 jam dalam Gambar 4(a), unsur aluminium dan titanium telah bergabung membentuk kepingan atau lamina. Jika waktu pengadukan semakin bertambah, maka bentuk lamina ini akan berubah menjadi gumpalan-gumpalan kecil dengan ukuran $\pm 4 \mu \mathrm{m}$ dan agak bundar karena terjadi peristiwa patahan dan pengelasan dingin yang berlangsung secara berulang-ulang seperti yang ditunjukkan dalam Gambar 2(b).

Gambar 5 menunjukkan spektrum EDX untuk paduan Al-10\%beratTi setelah dipadu selama 20 jam. Terlihat dalam Gambar 5, unsur aluminium dan titanium dapat diamati dengan baik. Selain $\mathrm{C}$ dan $\mathrm{O}$ yang berasal dari asam stearik [14] tidak ditemukan unsur-unsur lain. Hal ini menunjukkan bahwa teknik pemaduan mekanik telah berhasil menjadikan serbuk aluminium dan titanium sebagai binari paduan AlTi dengan tidak dicemari oleh unsur-unsur lain.

Gambar 6 menunjukkan pengaruh waktu pemaduan terhadap kekerasan paduan Al-10\% beratTi. Setelah pemaduan selama 2 jam kekarasan paduan Al-10\% beratTi adalah 244. Jika masa pemaduan semakin bertambah besar, maka nilai kekerasan Al-10\%beratTi juga semakin bertambah besar. Setelah pemaduan selama 30 jam kekarasan paduan Al-10\% beratTi adalah 514. Hal ini karena semakin bertambah waktu pemaduan maka semakin halus partikel paduan Al-10\%beratTi yang diperoleh seperti yang ditunjukkan dalam Gambar 4. Semakin halus partikel yang diperoleh maka pelet yang diperoleh menjadi semakin keras (Gambar 6) yang bermakna bahwa kekerasan semakin meningkat dengan bertambahnya waktu pemaduan. 


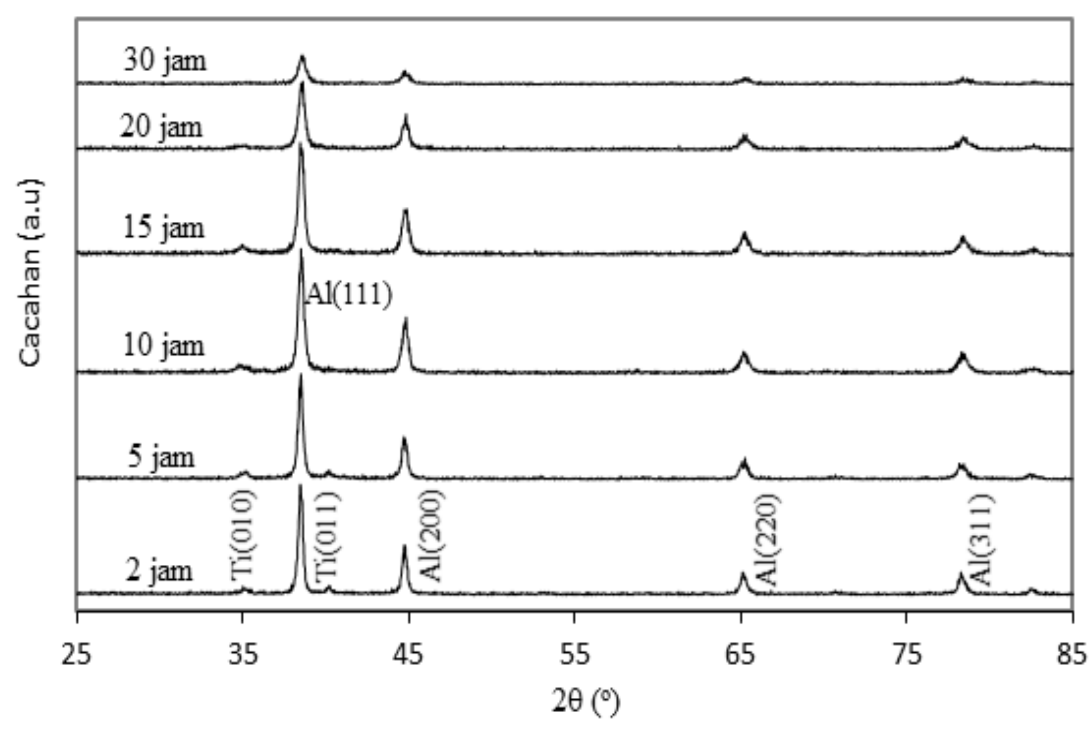

Gambar 2. Difraktogram XRD Serbuk Al-10\%Beratti Setelah Diaduk

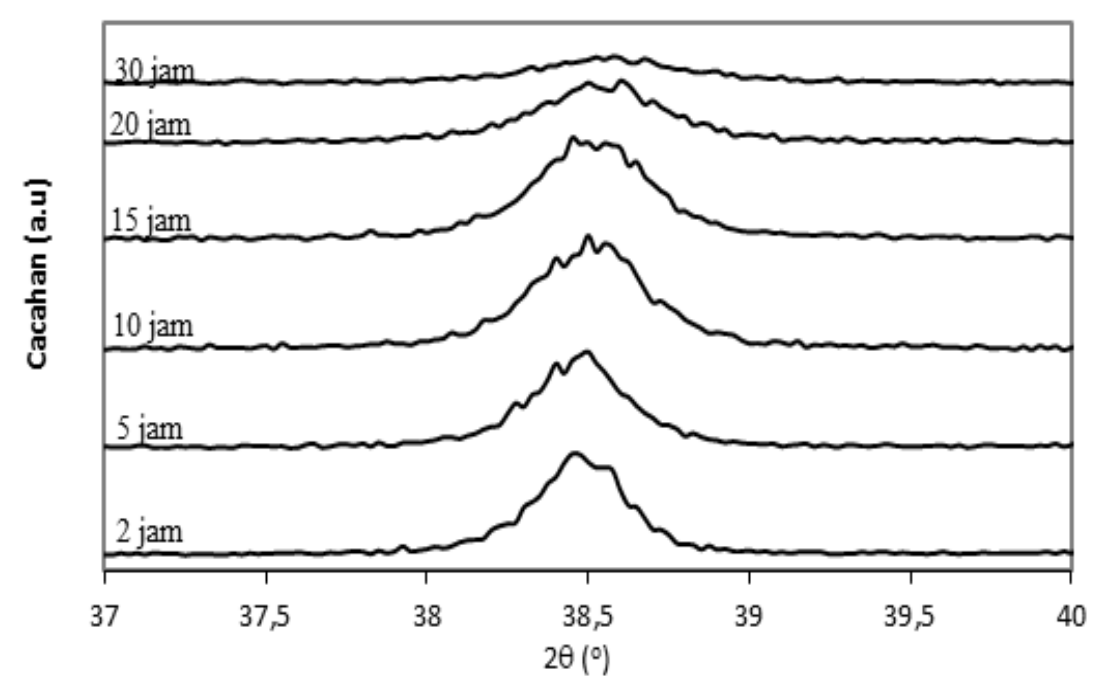

Gambar 3. Difraktogram XRD Serbuk Al-10\%Beratti Setelah Diaduk Untuk Puncak Al(111)

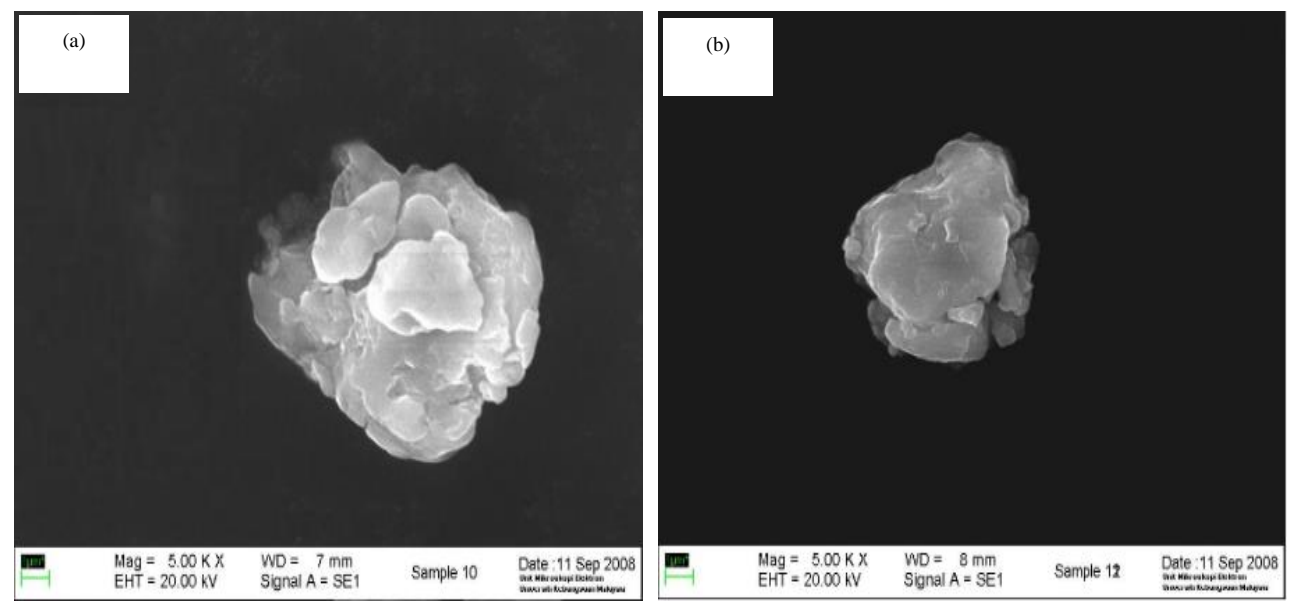

Gambar 4. Mikrograf SEM Paduan Al-10\%Beratti Yang Diaduk Selama :

(a) 5 dan (b) $20 \mathrm{Jam}$ 


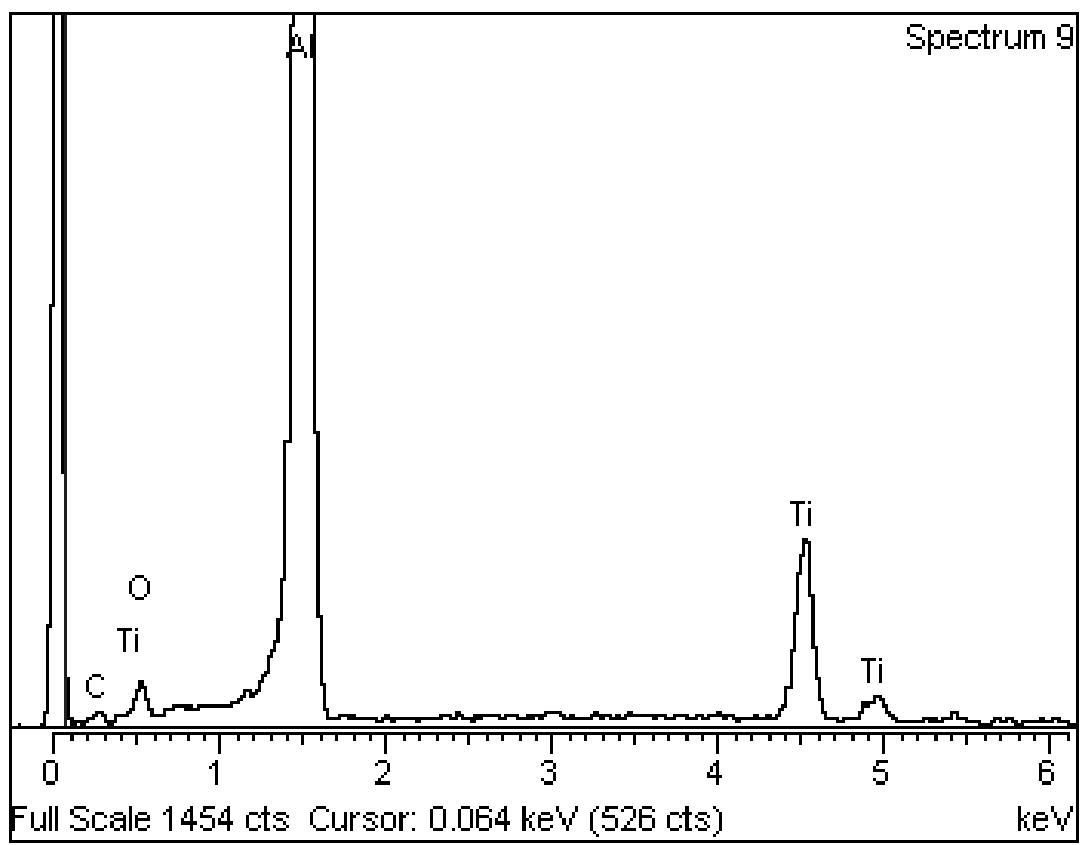

Gambar 5. Spektrum EDX Paduan Al-10\%beratTi Setelah Dipadu Selama 20 Jam

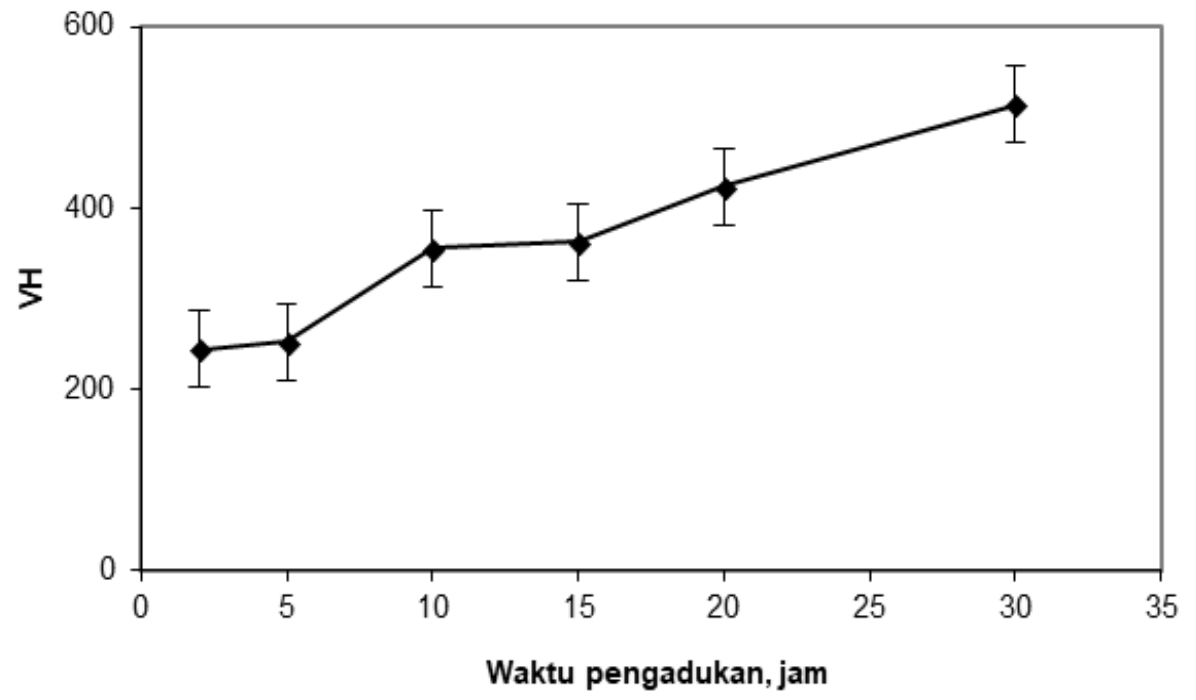

Gambar 6. Pengaruh Waktu Pemaduan Terhadap Kekerasan Paduan Al-10\%Beratti

\section{KESIMPULAN}

Dalam penelitian ini menunjukkan bahwa teknik pemaduan mekanik dapat menghasilkan paduan biner Al-Ti dan tidak dicemari oleh unsur-unsur lain. Semakin lama waktu pemaduan semakin cepat terbentuknya paduan Al-Ti. Hasil yang diperoleh dengan menggunakan SEM menunjukan bahwa semakin lama waktu pemaduan semakin kecil ukuran partikel serbuk paduan Al-Ti, yaitu mencapai ukuran $4 \mu \mathrm{m}$ setelah dipadu selama $30 \mathrm{jam}$. Semakin lama waktu pemaduan semakin besar kekerasan paduan Al-Ti karena semakin halus partikel yang diperoleh.

\section{UCAPAN TERIMA KASIH}

Penulis ingin mengucapkan terima kasih kepada Prof Abdul Razak Daud dan Prof Shahidan Radiman dari Fakulti Sains, UKM karena telah memberi nasehat dan bimbingannya. Tidak lupa, terima kasih juga penulis sampaikan kepada En Razali, En Yakub dan Pn Wati yang telah membantu dalam mengoperasikan instrumentasi di makmal, Fakulti Sains, UKM. 


\section{DAFTAR PUSTAKA}

[1] Li, X., Hui, D., Xuefong, R. and Yaoyao, R. 2007. Microstructures of mechanically activated Ti46at. \% A1 powders and spark plasma sintered ultrafine TiAl alloy. Rare Metals 26(6): 572 - 577.

[2] Xiaoying Zhu et al. 2006. Oxidation of Mechanically Allyed Al-rich Al-Ti Powder. Oxidation of metals 65: $357-376$.

[3] Lauer, St., Guan, Z., Wolf, H. and Wichert, Th. 2002. Investigation of mechanical alloying of Ti-Al compounds using perturbed $\gamma \gamma$-angular correlation spectroscopy, x-ray diffraction, and differential scanning calorimetry. J. Mater. Res. 17(8): 2130 - 2139.

[4] Calderon, H.A., Garibay-Febles, V., Cabrera, A., Cabanas-Moreno, J.G. and Umemoto, M. 2001. Mechanical Properties of Nanocrystalline TiAl-X and $\mathrm{TiAl}_{3}-\mathrm{X}$ Prepared by Mechanical Alloying and Sintering. Materials Science Forum 360-362: 229 - 234.

[5] Belyakov, A., Sakai, Y., Hara, T., Kimura, Y. and Tsuzaki, K. 2003. Metallurgical and Materials Transactions, 34A: $131-138$.

[6] Bonastre, J. 2007. Journal of Thermal Analysis and Calorimetry, 88(1): 83 - 86.

[7] Barona Mercado, W. et al. 2006. Hyperfine interact 169: 943 - 949.

[8] Chicinas, I., Pop, V. and Isnard, O. 2004. Journal of Materials Science 39: 5305 - 5309.

[9] Angelo L. D., Gonz'ales G. \& Ochoa, J. 2007. Phase Transformations Study on $\mathrm{Ni}_{75} \mathrm{Al}_{25}$ and $\mathrm{Ni}_{50} \mathrm{Al}_{50}$ during Mechanical Alloying and Sintering. Journal of alloys and compounds: $345-353$.

[10] Cao, G, Geng, L., Zheng. Z, \& Naka, M. 2007. The Oxidation of Nanocrystalline $\mathrm{Ni}_{3} \mathrm{Al}$ Fabricated by Mechanical Alloying and Spark Plasma Sintering. Intermetallics.15: 1672 - 1677.

[11] Enayati M. H., Sadeghian Z., Salehi, M and Saidi A. 2004. The Effect of milling Parameters on the Synthesis of $\mathrm{Ni}_{3} \mathrm{Al}$ Intermetallic Compound by Mechanical Alloying. Materials Science and Engineering A. 375 - 377: $809-811$.

[12] Cuevas, F.G., Cintas, J., Montes, J.M. and Gallardo, J.M. 2006. Al-Ti Powder Produced Through Mechanical Alloying for Different Time. J Master Sci 41: 8339 - 8346.

[13] Joshi, P. B., Marathe, G. R., Arun Pratap and Vinod Kurup. 2005. Hyperfine interactions 160: 173 180.

[14] Lu, L. And Lai M. O. 1998. Mechanical Alloying. Kluwer Academic Publisher, London 29. 